\section{QIJEI}

International

Journal for

Educational

Integrity

\title{
Faculty ethics logic of a religiously affiliated university
}

\author{
William R. Hanson, PhD \\ College of Business, Anderson University \\ HansonLLC@earthlink.net
}

Keywords: ethics, higher education, institutional ethics logic, grounded theory, religiously affiliated university

\begin{abstract}
This work responds to calls for ethics reform in higher education by exploring faculty realities of ethics logic within a small, religiously affiliated university. Research questions sought to discover what ethics entities existed, how they were related to each other, and how faculty members operationalised them. Using grounded theory methods and graph theory based analysis, the resulting Faculty Ethics Logic Model operationalised participant realities of the primary forces that drive teaching or resolving ethics issues at this particular university. That is, when emerging needs arose, faculty members derived response strategies primarily from knowledge, resources/artefacts, goals and beliefs; set within a framework of teaching or resolving ethics related issues, their resulting course of action was shaped by work-related contexts of group influence and collective norms. While the model did not exclude formal institutional influence, it highlighted the importance of informal elements within faculty realities (such as professional experience and desire for continued learning). Research implications pose the possiblitiy of using model construction to facilitate collective ethics logic understanding, or serve as a vehicle for discussing reform strategies. Triangulation of methods for data collection, analysis, and findings provide research trustworthiness.
\end{abstract}

This paper is based on an earlier version presented at The Center for Academic Integrity 2009 Annual International Conference.

\section{Introduction}

Recent ethical trespasses by institutional leaders and faculty have sometimes challenged the legitimacy of universities and colleges in America. Like many other systems around the United States (US), higher education has also undergone calls for ethics reform. However, while members of higher education call for student academic ethics reform (Hamilton, 2007; McCabe, Butterfield, \& Trevino, 2006; Moberg, 2006), ethical infractions by institutional leaders and faculty permeate professional literature and news (Bartlett, 2006; Gerber, 2005; Tierney, 2005; Van Der Werf, 2007). These ethical breaches reach across "individual/academic, departmental, sport programs, and organisational levels" (Kelley \& Chang, 2007, p. 412). This holds serious connotations for questions of who would conduct ethics reform, and what exactly, would be reformed. For example, reform of student ethical behaviour in universities may well require reform of higher education ethics as a whole. And that is the rub; while institutions across the US share many of the same ethics elements (Kelley, Agle, \& DeMott, 2006), each set must be tailored to the individual institution (Biggart \& Guillen, 1999). For this study, these ethics related

The International Journal for Educational Integrity is available online at:

http://www.ojs.unisa.edu.au/journals/index.php/lJEl/

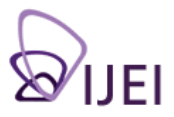


elements; that is, what faculty perceive as those institutional members and things that influence ethical thought and behaviour, are termed as ethics logic.

This work emerged from the concern that attempting to "reform" university ethics piecemeal, as much of the literature implied, would not fix systemic causes involving institutional structure and processes. To begin to find answers to this dilemma, this study focused on "discovery" of ethics logic grounded in a faculty perspective. Research questions sought to discover what ethics entities existed, how they were related to each other, and how faculty members operationalised them.

The purpose of this research was to begin to explore ethics logic through member realities at one small, religiously affiliated, private university. A qualitative study, ethics logic represents faculty realities in campus life that influenced ethics understanding and behaviour. Part of a larger study, this work first addresses the faculty role in ethics logic. It then presents a conceptual framework for ethics logic in higher education. Research methods and findings follow, where faculty realities were represented through a Faculty Ethics Logic Model. The model represented the primary forces that drove faculty teaching or resolution of ethics issues, unique to the institution under study. Discussion, conclusions and implications finalise this work.

\section{The faculty role in institutional ethics}

Faculty behaviour influences students and peers. Many educators feel ethical reflection and questions are far distant from daily life (Beckner, 2004; Reimer, Paolitto, \& Hersh, 1986). Yet, the public expects education to play a strong role in student learning of values and morals (Reimer, Paolitto, \& Hersh, 1986; Wong, 1998). College is an important time of student moral and character development - influenced when faculty members teach, advise, and counsel students in various capacities, whether as an instructor, academic advisor or campus club advisor. Not only is student development pushed by social and institutional forces, but the students themselves want to understand and learn how to deal with ethical challenges (Henle, 2006).

Faculty members also hold formal and informal leadership positions among peers - in campus roles and organisations, as well as professional associations. Campus roles include deanships, department and committee chairs, as well as faculty governing bodies. Professional collective roles include association officers, conference chairs and discussants, editors of scholarly publications, and many other functions. All of these roles involve ethical decision-making. Clausen also notes the importance of institutional members leading new members of an organisation to adhere to institutional norms (cited in Weidman, 1989/1999, p. 117). Academic integrity and other university values must be shared to achieve collective moral response and institutional legitimacy. Yet, this is not often the case (Fielden \& Joyce, 2008; Messick, 2006).

Literature reveals major ethical challenges for faculty, including unethical treatment of students and peers, a lack of ethics understanding by faculty in general, and little institutional support for faculty in resolving ethical issues (Knight \& Auster, 1999; Messick, 2006; Rhode, 2006). Hamilton (2007) warns that unethical faculty behaviour places academic freedom and professional autonomy at risk.

\section{Conceptual framework: Institutional ethics logic}

Institutional logics include beliefs, normative pressures, as well as "social and material expression in concrete practices..." (Biggart \& Guillen, 1999, p. 725). These constructs are influenced by both the institution's environment, and its pursuit of legitimacy (Evans, Trevino, \& Weaver, 2006). Ingrained in organisational 
understanding and culture, specific elements vary by group and context (Biggart \& Guillen, 1999). At the same time, in their study of ethics infrastructure at 100 universities, Kelly, Agle and De Mott (2006) note that many universities share a large selection of common ethics logic elements.

From an institutional perspective, organisations embody a set of shared values, norms and other entities that shape member beliefs and behaviour (Schein, 1992; Scott, 2001). These are embedded within human and nonhuman agent knowledge, and can be changed through agent interaction (Carley, 1999; Scott, 2001). Institutional agents take various forms - as individuals, artefacts, or aggregates representing groups or organisational sub-units. For example, a university's Institutional Review Board (IRB) can be viewed as both an aggregate (collective group of agents having similar views) or as a single agent. Artefacts also influence agent knowledge and behaviour, and include such things as law, policies, books, and websites; these agents hold and communicate knowledge, and can be connected to people in some way (Carley, 1999). Institutional agents are not considered "neutral" (Scott, 2001, p. 54). Official agents of the institution wield what Scott refers to as institutional regulatory attributes such as "force, fear, and expedience" (p. 53). For example, agents such as presidents, provosts, deans, and their representatives, can set policy, make campus-wide changes or decisions affecting entire colleges and departments.

\section{Research questions}

- What are faculty work-related ethical beliefs, knowledge, resources, agents and other ethics entities found within the institution?

- How are ethic entities related to each other, and to faculty members?

- How do faculty members operationalise ethics logic?

\section{Methods and design}

The researcher used grounded theory methods to understand faculty perceptions of institutional ethics logic. Based upon participant realities, grounded theory is discovery oriented and a primary method for examining processes (Creswell, 2003). It does not involve testing or verifying a priori hypotheses, rather it originates from formal research questions and employs open-ended questions and thematic analysis (Creswell, 2003; Strauss \& Corbin, 1990).

In this work, collection methods included using interviews, questionnaires, and artefacts. Analysis methods included adherence to Strauss and Corbin's (1990) rigorous coding methods (open, axial, selective). Analysis was aided by a software platform named the Organizational Risk Analyzer (ORA). Created at Carnegie Mellon University, ORA revealed complex, multi-ordered relationships, and assisted selective coding; that is, it explicated categorical relationships in terms of relational measures and corresponding quantitative values. Research trustworthiness was accomplished through triangulation of methods for data collection, data analysis and overall findings.

Research took place at a small private, religiously affiliated university employing 234 full-time and 109 part-time members. Both the institution under study and the researcher's IRB granted permission for the research. The research design consisted of two phases of data collection - interviews followed by an online survey.

\section{Participants}

The grounded theoretical sample for interviews was purposeful, seeking faculty and others noted by literature as playing an influential role in institutional ethics logic. The 
sample sought varying demographic views across sub-units and positions (different departments and tenure status). Criteria were achieved by obtaining a response rate between one and four from each of the major colleges, as well as from three university leaders in different administrative offices, each playing some role in institutional ethics. Thirteen faculty members and administrators of varying tenurestatus were interviewed.

For the second stage of research, interview data aided the development of an online questionnaire administered to the full-time faculty population. Selected participants included both the 76 faculty members at the college level, as well as 12 administrators holding faculty status. All 88 faculty members were invited to participate.

\section{Data collection}

Of the 13 interview participants, three were contacted to elaborate on responses, and three others were involved in multiple additional interviews. Collection of institutional artefacts and observations also contributed to the data. Data saturation was achieved after analysis of 10 responses, however all data was incorporated into the coding process. Interviews explored the participant realities of university ethics logic. (See Appendix A for a list of the open-ended, structured interview questions.)

Later, the online questionnaire allowed the faculty population to decide on abstracted themes and dimensions representative of collective reality. It acted as an intermediate member check, and provided data for the development of university ethics logic in subsequent analysis. The questionnaire was field tested at two universities. The response rate was $72 \%$, with 63 of the 88 participants completing the survey. (See Appendix B for a list of the online survey items and response choices.)

\section{Analysis}

Interview data were analysed using traditional methods of open, axial and selective coding; ORA assisted the selective coding process by providing quantitative measures and value representations for qualitative categories and concepts. The open coding process applied line-by-line analysis, and placed extracted meaning units into predefined categories derived from ethics-related literature. Axial coding abstracted meaning units, establishing higher order concepts. Table 1 presents examples of breaking data into meaning units, placing them into categories based on similar properties and dimensions (open coding), and then putting data back together through conceptual abstraction (axial coding). Set within a religiously affiliated institution, early analysis revealed a number of concepts, or elements, such as those found within institutional norms in Table 1, unique to a strong Christian environment. More of these elements emerged as coding continued, and are elaborated in subsequent findings. 
Table 1:

Example of data breakdown (open coding), then placing like concepts into categories through abstraction (axial coding)

\begin{tabular}{|l|l|l|}
\hline Open Coding (meaning units) & Category & $\begin{array}{l}\text { Axial Coding } \\
\text { (abstraction) }\end{array}$ \\
\hline $\begin{array}{l}\text { Respect for co-workers } \\
\text { Respect for the individual } \\
\text { Respect for the student } \\
\text { Respect for the Christian community } \\
\text { Value the individual student } \\
\text { Consider all stakeholders }\end{array}$ & Norms & Respect for others \\
\hline $\begin{array}{l}\text { Christian values and principles } \\
\text { Being a Christian university } \\
\text { Value of a Christian community } \\
\text { Christian values portrayed } \\
\text { Faith } \\
\text { Professed Christian faith } \\
\text { Religious practice }\end{array}$ & Norms & \\
\hline
\end{tabular}

Note: Meaning units were extracted from interview narratives, placed into a representative category, and later combined into an abstract concept. An iterative process of refinement, meaning units and concepts were sometimes moved to other categories, or category names were changed to accurately represent aggregated concepts.

Data coding produced 12 revised categories and 222 concepts. Table 2 displays the final categories, the number of concepts within each category, and the relational context. Categories and their corresponding concepts represented participant realities of work-related ethics entities, and answered the first research question, "What are member work-related ethical beliefs, knowledge, perceived pressures, agents and other entities found within the institution?".

Table 2:

Institutional categories and concepts composing university ethics logic

\begin{tabular}{|l|c|l|}
\hline \multicolumn{1}{|c|}{ Category } & Concepts & \multicolumn{1}{|c|}{ Relational Context } \\
\hline Sub-units & 6 & $\begin{array}{l}\text { Those colleges faculty interact with as part of job-related } \\
\text { tasks }\end{array}$ \\
\hline $\begin{array}{l}\text { Influential Groups (Formal } \\
\text { and Emergent) }\end{array}$ & 26 & $\begin{array}{l}\text { Those groups that influence faculty ethical behaviour } \\
\text { (committees, etc.) }\end{array}$ \\
\hline Ethics Artefacts & 15 & Those things that influence ethical behaviour \\
\hline Pressures & 33 & Institutional pressures noted by faculty \\
\hline Goals & 18 & Self-generated motivational pressures \\
\hline Ethics Knowledge & 16 & Knowledge faculty possess to fulfill ethics functions \\
\hline Ethics Tasks & 19 & Tasks central to teaching or resolving ethical issues \\
\hline Ethics Resources & 18 & $\begin{array}{l}\text { Resources used to conduct ethics tasks or resolve ethical } \\
\text { issues }\end{array}$ \\
\hline Ethics Resource Desired & 14 & Resources faculty would use, if available \\
\hline $\begin{array}{l}\text { Observed Unethical Behav- } \\
\text { iour }\end{array}$ & 22 & Behaviours noted by faculty as unethical \\
\hline Norms & 18 & Perceptions of institutional norms \\
\hline Beliefs & 17 & Beliefs or concerns possessed about campus life \\
\hline
\end{tabular}

Note. Concepts quantified in this table were included as response items to questions in the online survey and can be located in Appendix B. 
The selective coding process began with the collection of online survey data. With the aid of the ORA, questionnaire data established specific relationships between concepts and participants. Simply put, participants selected those concepts that represented their perspective of ethics logic; ORA allowed the researcher to measure the relationship between each concept and individual faculty member, as well as to the faculty collective. This data answered the second research question: "How are these entities related to each other, and to organisational members?".

The answers to the first two research questions provided the data and framework for institutional ethics logic, but it is the third question that helped apply that logic; that is, "How do faculty members operationalise ethics logic?". To begin to answer this question required further elaboration of data meaning, and prompted the researcher to ask questions of the data such as, "What do faculty members do with these elements?", and "How and why do faculty members apply them?". Answers to these kinds of questions established a perspective that, for faculty to teach or resolve ethical issues, they used certain elements of the institution's ethics logic. Hence, through a continued, iterative process of coding, teaching and resolving ethics related issues emerged as the core theme. Then, as part of this final coding process, related categorical relationships were integrated into a qualitative story and corresponding model (Strauss \& Corbin, 1990). This is provided in the next section.

\section{Findings: the faculty ethics logic model}

Categorical refinement through selective coding provided eight categories linked to the phenomena of teaching or resolving ethical issues: emergent job-related needs, faculty ethics knowledge, ethics resources and artefacts, faculty goals, faculty beliefs, group ethics influencers, ethical action, and faculty norms. Categories and their relationships are presented in Figure 1, which displays a conceptual Faculty Ethics Logic Model. The model addresses the "what" and "how" of ethics logic and does not explore variations in applications or changing conditions.

In their daily job-related activities, faculty faced a range of situations where they applied ethics logic as an all encompassing form of teaching or resolving ethics related issues. These wide-ranging needs were both routine and spontaneous, and were collectively represented as a causal condition that was situationally based (Strauss \& Corbin, 1990). This causal condition required faculty to apply ethics logic; yet to operationalise this process in varied situations, faculty were faced with integrating "broad and general" intervening conditions that facilitated or restricted resulting strategies (Strauss \& Corbin, 1990, p. 103). Conveyed on the left side of the model, the faculty aggregate primarily used ethics knowledge, as well as resources and artefacts to resolve ethical issues. Embedded within these conditions were dominating ethical beliefs and professionally related goals. Intervening conditions were based upon faculty realities, and not necessarily formal institutional standards, goals or policy. Within the phenomena of ethics logic application - that is teaching or resolving campus related ethical issues, resulting faculty actions or responses were shaped within a context of strong group influencers and norms. 


\section{Operationalized Faculty Ethics Logic Model Causal Conditions: Job-Related Ethics Need}

Intervening Conditions

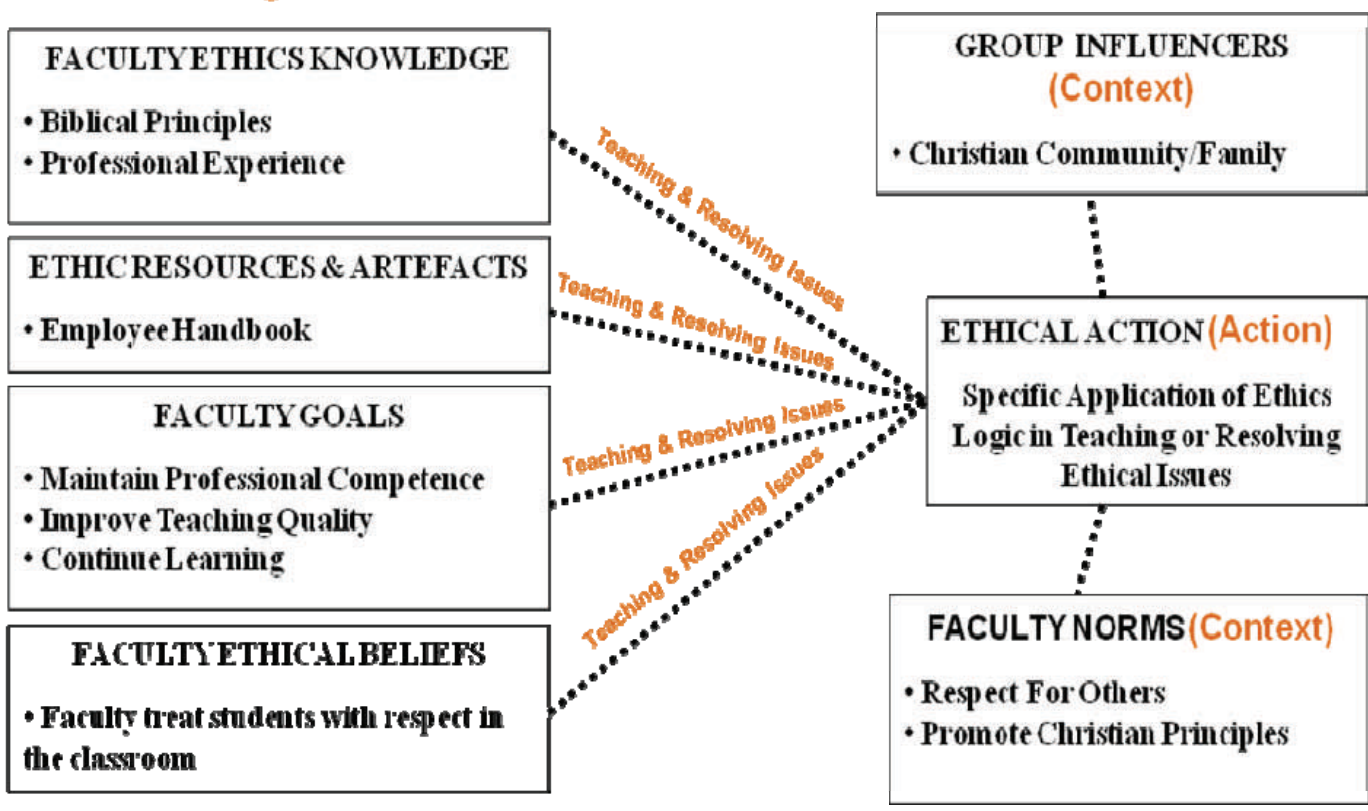

Faculty experienced job-related situations that prompted a need to teach or resolve ethics issues. Influenced by the Christian community and group norms, faculty determined a course of action by integrating ethics-related knowledge, resources and artef acts, as well as prof essional goals and beliefs.

Figure 1. Conceptual Faculty Ethics Logic Model explicating major forces involved in an emergent or routine need to teach or resolve ethics issues; influenced by the Christian community and group norms, faculty members determined a course of action by integrating ethics-related knowledge, resources and artefacts, as well as professional goals and beliefs.

\section{Causal conditions}

Faculty members possessed general, job-related needs to apply ethics in both the classroom and throughout the institution. Specific causes for the application of ethics logic were not always predictable; needs were based upon very general or changing situations. These causal conditions, created a requisite faculty action by applying ethics logic within a framework conceptualised as one of teaching or resolving issues (the phenomena). In this study, ethics teaching was not limited to a formal context of course curriculum, but also to all-purpose behaviour - such as role-modeling and other tasks of character development. The most central types of causal conditions expressed by participants included needs for modeling ethical behaviour, the application of biblical principles in their work, reviewing student work for plagiarism or cheating, and enforcing institutional policy. Faculty members also articulated a generic need to integrate ethics into academic courses. Formal, institutional applications - specifically the development of ethics codes, ethics policy, an ethics statement, and organisational values, were the least recognised as tasks with which faculty were involved. Faculty also identified concerns of resolving ethical infractions involving other faculty - but these expressions were infrequent. 
Intervening conditions pointed to a broad range of elements found within ethics knowledge, professional goals, ethics resources/artefacts, and beliefs. Each assisted or limited the faculty member's approach in teaching or resolving ethics-related issues. Faculty noted that the type of knowledge most enabling dealing with ethics issues included both biblical principles and professional experience. The significance of these two expressions revealed two strong and separate sources from which faculty drew knowledge to handle various issues. Of course, there were other elements, yet none holding the strength of these two forces. According to participants, lesser factors integrated into response strategies included that of seeking philosophical justifications or colleague wisdom; lesser still, was that of seeking the wisdom of administrators or the institutional community at large. Knowledge cited as holding little application included that of ethical theories, student development theories, and course materials.

The primary resource/artefact used in teaching or resolving ethics was the employee handbook, which incorporated factors of university policy and procedural steps to resolve ethic violations. Other notable resources/artefacts cited by faculty included the use of the Bible, peer groups, and professional values; these other resources/ artefacts held more than twice the centrality of such constructs as University mission, senior faculty, and scholarly writing or discourse. The Christian campus environment, along with university values and policies, played a minor role in faculty influence.

While faculty members recognised external pressures, such as budget constraints and workload (including committee work and student advising), this category did not garner significant reinforcement to identify it as a major influence in the role of teaching or resolving ethical issues. However, self-pressures in the form of professional goals revealed stronger substance. The most common professional goals that facilitated or constrained faculty member strategies included improving teaching quality, maintaining professional competence, and continued learning. Other goals expressed by participants as possessing moderate import included that of development of a reputable academic program, achieving leader effectiveness, and publication. Personal recognition and attaining an administrative position were the least mentioned goals.

Work-related ethical beliefs also played a significant role in university life; a primary force in faculty behaviour was that of showing respect for students in the classroom. Other beliefs that played a notable, yet less prominent, role were perceptions that faculty and senior leaders provided good ethical role models, that the University pursued higher levels of ethics practice than many other institutions, and that the institution was fair. Few members felt hesitant to raise ethical issues. In addition, most participants did not believe that ethical training for faculty or students was insufficient. Almost none of the participants felt the administration ignored minor ethical situations, or that racial discrimination was an issue on campus.

\section{Phenomena}

In this study, the emergent phenomena or central happening to which emerging actions and interactions were focused, took the form of teaching or resolving ethical issues. When asked what some of the top five ethics tasks they faced, nine of the 13 participants interviewed replied that it had to do with teaching ethics in some form. In addition, five of 13 included resolving ethics issues as one of the top tasks for them in campus life. In interviews, these two general topics often overlapped. Sometimes, "resolving" ethical issues took the generic form of "teaching". Faculty responses included:

- "Develop[ing] a Code of Ethics in a course."

- "Teaching ethics in core courses."

- $\quad$ "Teaching ethics to pre-service teachers." 
- $\quad$ "Teaching ethical concepts."

- " "Teaching ethics applications in our field."

- "Modelling and teaching ethical behaviours for future teachers."

- $\quad$ "Resolving ethical issues... including ethics in teaching materials presented to students."

- $\quad$ "Resolving ethical issues."

\section{"Develop policy for resolving ethics issues."}

This phenomena represents a process by which ethics logic is applied within a jobrelated framework. Thus, when an emerging ethics need arose (a causal condition), faculty derived response strategies primarily from the knowledge, resources/artefacts, goals and beliefs (intervening conditions), with an intent to shape a lesson (teach) or resolve an issue, and the resulting course of action was influenced by a work-related context of group influence and norms.

\section{Context}

A Christian environment surrounded the University, where religion played a large part of university life. A chapel was located on campus, and there were ministers teaching theology courses. By far, the Christian community/family, as a collective agent, occupied a dominant role in influencing faculty strategies. Peers also played a notable role, yet they appeared as a distant second. Groups such as students and deans were less than half as influential, while committees and external campus stakeholders such as the University accreditation agency and the organisation to which the University was affiliated held even less faculty influence.

Faculty highlighted what they believed to be strong institutional norms. In particular, they believed that two of the most powerful norms influencing their actions were a general respect for others and the promotion of Christian principles. Other significant norms included kindness, integrity and the practice of moral behaviour. Practicing family values and leadership excellence were two of the least cited norms practiced at the University.

\section{Action}

Teaching or resolving ethical issues was based upon a specific, routine or emerging issue (i.e., incivility, cheating, etc.) and place (classroom, committee, etc.), and therefore prompted varied individual response. While some issues were recognised in the quotes identifying the phenomena - such as developing a code of ethics in the classroom or applying ethics to a particular field - these did not capture the spectrum of issues with which faculty dealt. Moreover, how one faculty member responded to an issue in the classroom may well have been different when faced with the same issue in a faculty meeting. This study did not attempt to identify the realm of issues and the specific resulting action taken by faculty, but merely identified the faculty response as an "action" in the most generic sense.

\section{Discussion}

This work stemmed from a concern that to initiate solid reform requires an understanding of the holistic relationships of ethics logic in the work place. Faculty fulfilling strong influential roles in student ethical development was a logical start. Research findings answered the three research questions, generating: 1) work-related entities and elements important to faculty in their daily campus life, 2) the number and pattern of links between participants and ethics-related concepts, and 3) the way collectively, that faculty operationalised ethics logic in teaching or resolving ethics issues. The proposed model incorporated dominant forces in the application of ethics logic as a process in which faculty sought to teach and resolve ethics issues at a religiously affiliated university. The model represented the primary forces that drove 
faculty teaching or resolution of ethics issues; it recognised that many faculty members share some of the same knowledge, beliefs, contexts, and other factors that guide ethics-related behaviour. The model explicated the dynamics involved in faculty action to teach or resolve ethical issues. It revealed that intervening conditions held potent individual differences (such as each member's goals and beliefs); yet, at the same time, it implied these differences were under pressure to conform to forces of groups and norms. While the model did not completely exclude formal institutional influence, it highlighted the importance of the emerging nature of outcomes largely from faculty response and not formal mechanisms of hierarchy and institutional policy. This is an important foundation for future concepts in institutional ethics reform.

While this research found many of the same ethics elements noted in literature, some were new, emerging from participant interviews. At the same time, some elements originating from institutional artefacts, like the University website and various ethicsrelated policies, failed to display significance with participants. Findings suggest that many ethics logic elements are generated by the users, and that the efficacy of a university's ethic logic is in the operationalisation of those elements. In other words, an institution's ethics system can not be wholly forced upon institutional members, particularly if members do not recognise or apply related elements in their work. This involves two distinct considerations for higher education leaders. First is that many informal institutional principles originate from faculty and should be actively nurtured. Principles can be fostered among members (as professionals) and among students. Secondly, and specifically addressing reform, this study reveals that much of reform rests with faculty. Faculty knowledge, goals, and beliefs played a significant role in teaching or resolving ethics-related issues. Teachers are considered leaders and agents of change (Chapman, 2006; Garcia Barbosa, 2000), and must be considered as primary change agents in ethics reform for students and the institution. For faculty this implies they must help create, know and enforce the ethical principles of the institution - not all of which are captured in written institutional instruments; reform holds ethical responsibilities for faculty as well as students.

\section{Conclusion}

Literature on ethics reform in higher education has consistently addressed serious issues and the need for reform over the last few decades. While there is significant literature on group norms and organisational culture in universities, ethics is rarely discussed as a holistic system composed of job-related elements and people. Further, because it is socially based, and as a logic it is considered varying among groups, ethics is rarely analysed as a set of elements possessing common relevence to differing groups.

This research tackles some of the major challenges facing ethics reform in higher education institutions. Exploring faculty perceptions at the institution under study, it captures ethics elements not always addressed in research - such knowledge and institutional groups playing influential roles in work-related ethics contexts - identified by organisational members. It also captures the relationships between members and university elements within a process of ethics application. Operationalising institutional processes hold vast potential for member ethics understanding and strategies for reform. This work also underscores the concern that attempting to "fix" specific issues or "areas" such as student ethical problems may be difficult if other institutional influences and parts are not taken into consideration.

This paper also supports and extends the work of Kelley et al. (2006), which brought into focus what they called the infrastructure supporting ethical behaviour in higher education. Some of the elements identified by these authors also emerged from participant interviews in this study. Yet, by having participants generate what they believed were influencers and their corresponding strengths, this study added others - some possibly unique to the institution under study. Also, this work placed these 
elements within a perspective elaborating the connectivity these elements hold with a faculty member aggregate.

\section{Implications for ethics research}

Findings, particularly the generation of survey response items, can assist future ethics research. Diversity between higher education institutions should not be allowed to dismiss many of the generalised findings originating from a single institution as lacking relevance to other institutions (private/public, research/liberal arts, small/ large). As noted earlier, this study found that many of the same ethical issues and elements noted in literature also existed at this small, religiously affiliated university (see Kelley et al., 2006). In other words, when building ethics logic survey items, researchers can be aided by existing lists of ethics elements in other works particularly those generated by like participants. It is true that some conditions and context differ - there may be many elements important to a religiously affiliated institution and not others. However, shared commonalities among various organisational cultures are not uncommon (Schein, 1992) and represent one of the powers of qualitative generalisabilty for theoretical development (Strauss \& Corbin, 1990). Generalisability in this work is expressed by the following two points. First, it may well be that there are varying degrees of import for each logic element. For example, it might be stated that plagiarism is an issue for consideration at all universities, yet the strength or degree of plagiarism offense and enforcement might vary widely; in other words, the significance of an ethical element such as plagiarism may be important - whether it holds a value of zero or 100 . Another example is that while faculty knowledge, beliefs, and norms may be different at each institution, these and other general themes may hold utility across institutions. This is certainly a promising area for future research.

\section{Implications for reform}

Ethics reform implications for higher education instituions are twofold. First, approaching reform efforts from a holistic perspective with member input, as done in this study, sheds light on what members consider to be the most influential elements in each institution's ethics logic. Having faculty participate in this process may help address a serious issue pointed out earlier in the paper - specifically, research pointing to a general lack of ethics understanding by faculty (Knight \& Auster, 1999; Messick, 2006; Rhode, 2006). Constructing a faculty ethics logic model may facilitate collective understanding, or at least serve as a collective vehicle for discussing reform strategies. Along this line of thought, future research comparing the perspectives of differing groups, such as faculty and administration, or faculty and students, might hold significant value. This process may show group variences between elements and process, bring greater collective understanding to the issues that each must address, and aid the reform movement by informing members on what elements seem to hold more efficacy for ethical behaviour at their institution - within their culture.

Secondly, comparing institutional models may also shed light on similarities and variations among each. For example, can it be safely assumed that most universities may not hold the Bible as an important artefact in daily campus life, or expect faculty to formally exercise biblical principles in their strategies addressing ethics workrelated issues? More to the point, the question might be, what set of shared principles do faculty and staff use to resolve ethical issues, if any? Also, comparison of institutions may hold particular implications for decentralised institutional collectives, such as a set of university institutional satellites programmes. Would the ethics logic models among institutional sub-units hold significant variances? Should they?

This study reveals the complexity of relationships and perceptions of ethics in daily campus life. Ethical thought and behaviour are a part of everyday experience and involve a host of ethics-related constructs such as ethics knowledge, ethics resources, artefacts, goals, and influence of various stakeholders. Higher education and its members hold ethical developmental responsibilities to students, to each 
other, and to the legitimacy of the university - an institution with societal obligation and influence.

\section{About the author}

William Hanson serves as a leadership consultant, and as an adjunct professor teaching Leadership and Ethics in the MBA program at Anderson University. He has 25 years of experience in leadership positions, as well as 10 years of teaching leadership in higher education. William earned his PhD in Educational Leadership at Clemson University. His research focus is on leadership and ethics, set within a complexity theory framework.

\section{References}

Bartlett, T. (2006, August 4). Southern Illinois chief fights copying charge. The Chronicle of Higher Education, A10.

Beckner, W. (2004). Ethics for educational leaders. Boston, MA: Pearson.

Biggart, N. W., \& Guillen, M. F. (1999). Developing difference: Social organization and the rise of the auto industries of South Korea, Taiwan, Spain, and Argentina. American Sociological Review, 64(5), 722-747.

Carley, K. (1999). On the evolution of social and organizational networks. JAI Press special issue of Research in the Sociology of Organizations, 16, 3-30.

Chapman, J. M. H. (2006). Collaborative early intervention program teachers' roles as change agents in relationship to current change theory. Unpublished doctoral dissertation, University of West Georgia.

Creswell, J. (2003). Research design: Qualitative, quantitative, and mixed methods approaches (2nd ed.). Thousand Oaks: Sage.

Evans, J., Trevino, L., \& Weaver, G. (2006). Who's in the ethics driver's seat? Factors influencing ethics in the MBA curriculum. Academy of Management Learning \& Education, 5(3), 278-293.

Fielden, K., \& Joyce, D. (2008). An analysis of published research on academic integrity. International Journal for Educational Integrity, 4(2), 4-24.

Garcia Barbosa, T. J. (2000). Master Class: Exploring innovative practice in educational leadership; a study of change, complexity, culture and community in co-creating learning organizations. Unpublished doctoral dissertation, The Ohio State University.

Gerber, L. G. (2005). Auburn University: A case study in the need for sunshine. Academe, 91(3), 32-33.

Hamilton, N. W. (2007). Faculty autonomy and obligation. Academe, 93(1), 36.

Henle, C. A. (2006). Bad apples or bad barrels? A former CEO discusses the interplay of person and situation with implications for business education. Academy of Management Learning \& Education, 5(3), 346-355.

Kelley, P., Agle, B., \& DeMott, J. (2006). Mapping our progress: Identifying, categorizing and comparing universities' ethics infrastructures. Journal of Academic Ethics, 3(2), 205-229.

Kelley, P., \& Chang, P. (2007). A typology of university ethical lapses: Types, levels of seriousness, and originating location. The Journal of Higher Education, 78(4), 402-429.

Knight, J., \& Auster, C. J. (1999). Faculty conduct: An empirical study of ethical activism. Journal of Higher Education, 70(2), 188.

McCabe, D. L., Butterfield, K. D., \& Trevino, L. K. (2006). Academic dishonesty in graduate business programs: Prevalence, causes, and proposed action. Academy of Management Learning \& Education, 5(3), 294-305. 
Messick, D. (2006). Three barriers. In D. Rhode (Ed.), Moral leadership: The theory and practice of power, judgment, and policy (pp. 95-110). San Francisco, CA: Jossey-Bass.

Moberg, D. J. (2006). Best intentions, worst results: Grounding ethics students in the realities of organizational context. Academy of Management Learning \& Education, 5(3), 307-316.

Reimer, J., Paolitto, D. P., \& Hersh, R. H. (1986). Promoting moral growth: From Piaget to Kohlberg (2nd ed.). New York: Longman.

Rhode, D. (2006). Introduction: Where is the leadership in moral leadership? In D. Rhode (Ed.), Moral leadership: The theory and practice of power, judgment, and policy (pp. 1-53). San Francisco, CA: Jossey-Bass.

Schein, E. H. (1992). Organizational culture and leadership (2nd ed.). San Francisco, CA: Jossey-Bass.

Scott, W. R. (2001). Institutions and organizations (2nd ed.). Thousand Oaks, CA: Sage.

Strauss, A., \& Corbin, J. (1990). Basics of qualitative research: Grounded theory procedures and techniques. Newbury Park: Sage.

Tierney, W. G. (2005). When divorce is not an option. Academe, 91(3), 43-46.

Van Der Werf, M. (2007, August 10). Ethics policies raise concerns for business officers at annual meeting. The Chronicle of Higher Education, A21.

Weidman, J. (1989/1999). Undergraduate socialization: A conceptual approach. In J. L. Bess \& D. S. Webster (Eds.), Foundations of American Higher Education (pp. 114-135). Boston, MA: Pearson Custom Publishing.

Wong, K. (1998). Culture and moral leadership. Peabody Journal of Education, 73(2), 106-125. 


\section{Appendix A: Structured Interview Questions}

1. What are the top-five values at your university that influence the ethical behaviour of faculty?

2. What are the top-five agencies or groups that influence the ethical behaviour of faculty?

3. What are the top-five things (artefacts) that influence faculty ethical behaviour at your university?

4. What top-five work-related pressures do you and your colleagues face on campus?

5. As related to higher education in general, what top-five personal goals or accomplishments do you want to achieve in higher education?

6. What are the top-five kinds of ethics knowledge or expertise held by you or your colleagues that assist in ethics teaching, decision-making or resolving ethical issues?

7. What are the top-five work-related tasks you or your colleagues do that is related to ethics?

8. What are the top-five resources you and your peers use to reinforce ethical understanding or resolve ethical issues?

9. What are the top-five resources that you or your peers would like to add to university structure, which would allow greater reinforcement of ethical understanding or resolve ethical issues?

10. List faculty unethical behaviours that you have seen or learned about while at this institution? (Limit to the last four or so years.)

11. What are your top-five beliefs/concerns regarding ethics and ethical behaviour at your university?

\section{Appendix B: Abbreviated Online Survey Questions}

Question response items represent thematic abstractions generated by faculty interviews, artefacts, and theoretical sensitivity. Belief questions and other questions not used in this study were removed due to space constraints.

1. What agencies or groups most influence your ethical behaviour? Choose all that apply.

Faculty Meetings

College Meetings

Administrators

Deans

Department Chairs

Senior Leadership (Provost, President, Etc.)

Peers

Students

South Carolina Baptist Convention

Human Resources Department

Student Development Staff

Internal Planning Group

Faculty Governance Coordination Team

Academic Programs and Policies Committee

Faculty Status Committee

Faculty Development Committee

Faculty Concerns Committee

Faculty Advisory Council to the [Name] University Abroad Committee 
Excellence in Teaching Committee

Teacher Education Committee

Human Subjects Committee

Animal Care and Use Committee

Athletic Oversight Committee

Retention and Advising Committee

Southern Association of Colleges and Universities (SAC)

Christian Community/Family

2. What artefacts most strongly influence your ethical behaviour at [Name]

University? Choose all that apply.

Bible

Faculty Hand Book

Christian Institution/Environment

Course Material

Laws

University Policies

Unwritten Norms

Ethics Code

University Mission

University Values

Professional Values

Departmental Values

Scholarly Writings

Scholarly Discourse

Senior Faculty

3. Select the primary source(s) of pressure you feel in the context of university life.

Choose all that apply.

Writing Grants

Meeting Organizational Goals

Accreditation

Required Certifications

Seeking Tenure

Motivating Students

Community Service

Institutional Service

Fund Raising

Scholarship

Receiving Job Evaluations

Student Course Evaluations

Tenure Requirements

Promotion Requirements

Post-Tenure Review

Budget Constraints

Lack of Resources for Academic Program Goals

Teaching Excellence/Instructional Expectations

Adding New Programs

Institutional Growth

Peer Expectations

Administrative Expectations 
Student Retention

Student Recruitment

Student Advising

Preparing Reports

State Mandates

Balancing Work and Family

Acclimating to Religious-Private vs. Public Institution

Work Load

Committee Work

Professional Development

Achieve Terminal Degree

4. What personal goals or accomplishments do you want to achieve in higher education? Choose all that apply.

Maintain Professional Competence

Achieve/Maintain Technical Competence

Achieve Administrative Position

Achieve Terminal Degree

Achieve Higher Academic Rank

Student Service

Develop Reputable Program

Improve Teaching Quality

Community Service

Institutional Service

Conduct Research

Publish

Achieve Financial Security

Continue Learning

Be an Effective Leader

Reduce Unit Bureaucracy

Tenure

Recognition

5. What type of ethics knowledge assists you in with such things as ethics

teaching, decision-making or resolving ethical issues? Choose all that apply.

Biblical Principles

Sound Philosophical Justifications

Academic Ethic Theories

Student Developmental Theories

Professional Experience

Professional Association Ethics Code

Discipline Ethics Code

South Carolina Code of Ethics for Teachers

Student developed Course/Club Written Ethics Code

Higher Education's Value of Truth

Altruistic Motivation

College Committee Knowledge

Wisdom of Colleagues

Wisdom of Administrators

Research Results

Course Materials 
6. In the list below, which best describes the ethics tasks you perform in your work? Choose all that apply.

Teach Ethics to Faculty and/or Staff (Seminar or Class)

Enforce Institutional Ethics Policy

Review Documents for Ethical Content (Research Proposals, Expenditures, Etc.)

Review Student Work for Plagiarism/Cheating

Resolve Student Ethical Issues

Resolve Faculty Ethical Issues

Teaching an Ethics Course

Integrating Ethics within a Course

Teaching Ethics Applications in Field

Facilitating Ethical Scenarios

Developing Unit Ethics Statements

Developing Unit Mission and Values

Developing a Code of Ethics

Developing Ethical Policy

Knowledge of Academic Polices

Observance of Academic Policies

Modeling Ethical Behaviours

Integrating Ethics within Scholarship

Application of Biblical Principles

7. The following resources are available at [Name] University. Which would you likely use to resolve ethical issues? Choose all that apply.

Committees

Sources outside the Institution

Training

Teaching

Bible

Chapel

Employee Handbook

University Values

Laws or Policies (various personnel policies, etc.)

Textbooks

Guest Speakers

Academic Leaders

Professional Associations

Meetings

Student Learning Outcomes

Peers Working on Common Tasks/projects

Course Syllabi

Student Development Guide

8. Which of the following best represent norms practiced at [Name] University?

Choose all that apply.

Respect for others

Respect for authority

Respect for property

Institutional Loyalty

Integrity 


\section{Fairness}

Kindness

Responsibility

Promotion of Christian principles/values

Practicing family values

Practicing academic values

Good stewardship of resources

Furthering/teaching ethical understanding

Practicing moral behaviour

Teaching Excellence

Leadership Excellence

Professional Excellence

Quality Improvement 